\title{
Lithologic Characterization and Micropore Structures of Gas Shale Strata: An example from the Midra Shale of Western
}

\% ESC Qatar

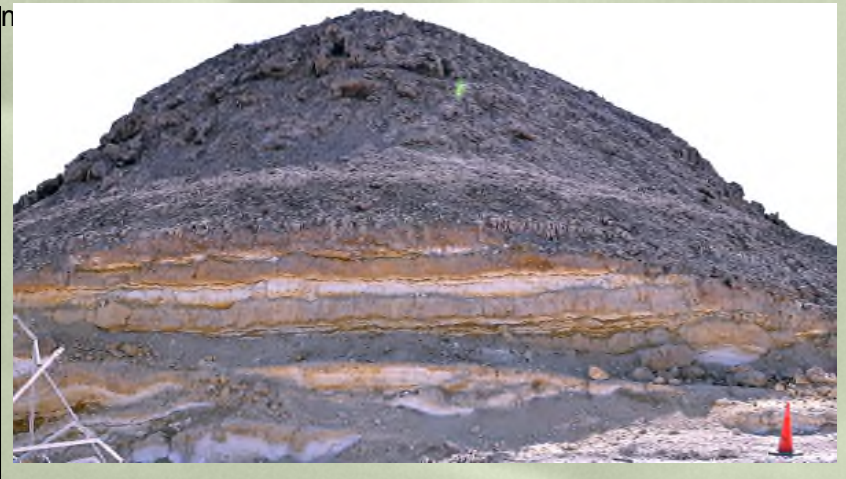

Outcrop of the Midra Shale in Dukhan Area

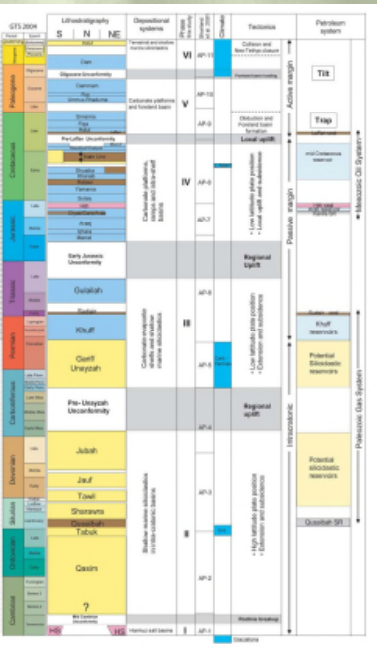

The Midra Shale is the lower member of the Eocene Dammam Formation. This Formation forms a major part of Qatar's surface geology. It consists mainly of limestone and dolomite with subordinate amounts of shale and marls. Although the Midra was derizons were consid as as indiction of depostion under reth Bab area, a section made of carbonate mud with angular, large lithoclasts of argillaceous materials. This part is interpreted as ). The shale is present as thin laminations with pinkish iron staining alternating with white carbonate materials accumulated as thin shaposited in a marine shelf that was subjected to clastic influx from the nearby land. Some of thes them away from the shoreline.

The presence of halite and gypsum within the Midra lithologies may suggest that these were gypcrete and "halcrete" formed by the evaporation of groundwater seeping upward in the relatively porous lithologic components of the Midra because of the high Geochemistry

Samples were collected from the type locality of the formation in Dukhan area and from the newly excavated roads in Umm Bab area. These were analyzed for their chemical elements and oxides using X-Ray Diffraction and X-Ray Fluorescence. The rocks were found to consists mainly of the clay mineral palygorskite with lesser amounts of other clay minerals such as illite, smectite and sepiolite. There two types of palygorskite; the $\mathrm{mg}$ series and the Al series. Other non-clay minerals include calcite, gypsum, and halite. Some of the samples were examined under the Scanning Electronic Microscope (SEM) and the Transmission Electron Microscopy (TEM) to study crystal geometry and pore structures. The palygorskite is formed of long, rectangular laths with channels
running parallel to these laths. Others are formed of bundled lath-like crystals of palygorskite 5 to $20 \mathrm{~nm}$ in width and several micrometer in length. Gypsum and halite are present as massive groundmass, but cubic halite crystals were also found. There are some fibrous, feather-shaped crystals of iron. Iron is common in most of the Tertiary sediments of Qatar.

X-Ray graph showing the main mineralogica (van Buchem et al. 2014).
(van
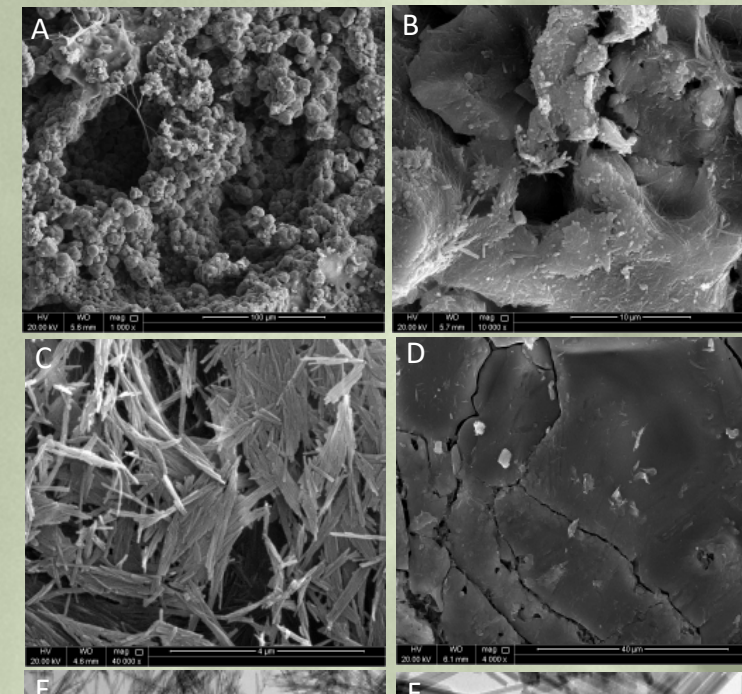

A. Well-developed halite cubes growing amid palygorskite fibers and laths. This halite is probably diagenetic in origin formed by the evaporation of the upward moving groundwater to cubes grow for and

B. Interlocked euhedral halite crystal forming the groundmass of some of the shale sediments. These are most probably gypcrete deposited by the upward moving

C. Feldspar crystal in the middle of calcite and clay grains. Feldspar is most probably detrital moved from the nearby land either by wind or flowing streams. D. Iron concretion. Iron is a second

E. Fibrous crystal of iron roses filling a space between sheets of other clay minerals. These are mostly diagenetic in origin.
E.

F. Massive gypsum crystals. These are cement precipitated by the percolating CaSO4 enriched meteoric water. They are common in many of the Tertiary carbonate sediments all over eastern Arabia.

The heterogenous lithology of the Midra Member, the fibrous-lath shaped structure of the palygorskite and the presence of a considerable amount of evaporites (1) Dics and hastice (1) Dissolution micropores resulted by the selective dissol

(3) nano pores inside some of the laths (4) micro and nano fracture of the groundmass of some of the lithologies.

1. The Midra Shale is the lower member of the Eocene Dammam Formation which covers the large parts of Qatar.

2. The Member consists of shale with some carbonate mudstone and marl with some large foraminifera, shark teeth and shell fragments.

3. The Midra was deposited under a shallow marine shelf th

The

4. Geochemical analyses using both XRD and XDR indicate that the studied rocks

sepiolite. Other minerals present include calcite, quartz, gypsum and halite.

The present evaporite (gypsum and halite) may be formed by the evaporation
part of the sediments due to high evaporation under arid climatic conditions.

SEM and TEM examination of the palygorskite suggest that this mineral is formed of loosely-packed fibers and laths associated with longitudinal channels that

represent important micropores.

Microporosity in the studied samples are either primary resulted from the loose struc

8. The Midra Shale provide a good example of the nature of the gas shale reservoirs in Qatar.
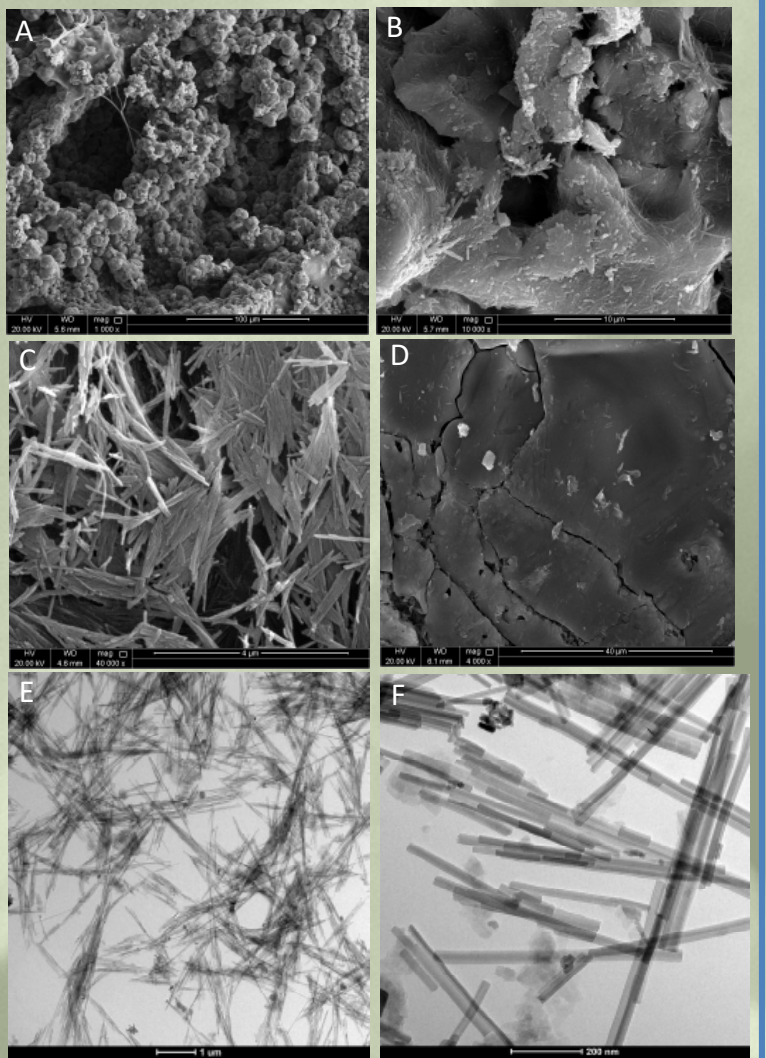

B. Interface microporosity. This type of porosity results from the loose packing of differen components leaving spaces betwe or the This may be inher nvironment or generated by later diagenetic processes.

C. Intercrystalline microporosity between the fibers and laths of the palygorskite clay mineral. D. Microfracture porosity in a halite groundmas. These fractures are either the result of stress resulted from recrystallization and crystal growth or from tectonic stress.

TEM micrograph showing detailed intercrystalline porosity in palygorskite.

laths have less density). The light-colored laths have channel porosity.
later 